Jurnal Inkofar * Volume 1 No. 1 Juli 2019 * ISSN: 2615-3645 (Print) / 2581-2920 (Online)

Tersedia secara online di: http://www.politeknikmeta.ac.id/meta/ojs/

\title{
RANCANG BANGUN SISTEM INFORMASI PRODUKSI HOSE COME FUEL FEED PADA PT TOKAI RUBBER AUTO HOSE INDONESIA BEKASI
}

\author{
Asep Dony Suhendra ${ }^{1}$, Ratih Dwi Asworowati ${ }^{2}$, Windi Wijaya ${ }^{3}$ \\ ${ }^{1}$ Administrasi Bisnis / Nama Fakultas / Universitas Bina Sarana Informatika / asep.aya@bsi.ac.id \\ ${ }^{2}$ Sistem Informasi / Teknologi Informasi / Universitas Bina Sarana Informatika / ratih.tww@bsi.ac.id \\ ${ }^{3}$ Sistem Informasi / Teknologi Informasi / Universitas Bina Sarana Informatika / \\ asmara2wijaya@gmail.com
}

\begin{abstract}
Development of communication and technology in the present has gone very quickly. In addition to being driven by the demands of progress and lifestyle, the pattern of thinking in technological development must participate in having a revolution for improvement and fulfillment, including in the field of business. PT. Tokai Rubber Auto Hose Indonesia, which is still in the process of developing and depend results of product sales to survive in the competition in the world of the industry would require a development in information management, especially the production environment. In this case the author tries to make the final task of production information system hose come fuel feed at PT. Tokai Rubber Auto Hose Indonesia, which until now has not been computerized, the current system still uses manual recording starting from ordering material using paper form and production reporting process which only done in one process only, until production reporting for suppervisor done manually that other than difficult to control stock of goods, also data collection that still use Ms. Excel certainly have potency of error and less accurate from facet of data and also takes longer in making report. Computerized system would be more profitable for the company. In addition to the efficiency of time, level of production data errors can also be minimized so that the system is better controlled.
\end{abstract}

Keywords: System, Information, Design, Production

\begin{abstract}
ABSTRAK
Pengembangan komunikasi dan teknologi di masa kini sudah melaju dengan sangat cepat. Selain didorong oleh tuntutan kemajuan dan gaya hidup, pola berfikir dalam pengembangan teknologipun harus turut serta memiliki revolusi untuk perbaikan dan pemenuhan kebutuhan termasuk dalam bidang bisnis. PT. Tokai Rubber Auto Hose Indonesia yang saat ini masih dalam proses pengembangan dan mengandalkan hasil penjualan produk untuk bertahan dalam persaingan didunia industri tentu memerlukan adanya perkembangan dalam management informasi khususnya dilingkungan produksi. Dalam hal ini penulis mencoba membuat Tugas Akhir mengenai sistem informasi produksi hose come fuel feed pada PT. Tokai Rubber Auto Hose Indonesia yang sampai saat ini belum terkomputerisasi, sistem yang ada pada saat ini masih menggunakan pencatatan manual mulai dari pemesanan material yang menggunakan form kertas dan proses pelaporan hasil produksi yang hanya dilakukan di salah satu proses saja, hingga pelaporan produksi untuk suppervisor dilakukan secara manual yang selain sulit untuk dikontrol stock barangnya, juga pendataan yang masih menggunakan Ms.Excel tentu banyak memiliki potensi kesalahan dan kurang akurat dari segi pendataan serta membutuhkan waktu yang lebih lama dalam pembuatan laporan. Sistem yang terkomputerisasi akan lebih menguntungkan bagi perusahaan. Selain untuk efisiensi waktu, tingkat kesalahan pendataan hasil produksi juga dapat diminimalisir agar sistem lebih terkontrol dengan baik.
\end{abstract}

Kata Kunci: Sistem, Informasi, Perancangan, Produksi

\section{PENDAHULUAN}

Kunci utama dalam sebuah perusahaan tentunya adalah berjalanya aktifitas produksi yang menjadi sumber utama penghasil produk yang akan dijual. Dalam aspek kebutuhan informasi produksi, bukan hanya terkait pada proses produksi itu sendiri namun permintaan bahan baku juga harus dapat diolah data informasinya agar dapat lebih terkontrol jumlah bahan baku yang dipasok ke area produksi. Selain itu pencatatan hasil produksi yang masih menggunakan metode penulisan mengguanakan 
media kertas tentu harus diolah kembali agar dapat dilaporankan kepada pihak management. Namun saat ini pengolahan data hasil produksi masih menggunakan Ms.Excel dan hal ini membutuhkan waktu lebih lama dikarenakan untuk mendapatkan hasil stock secara data memerlukan pencocokan dari data yang satu ke data yang lainnya.

Dalam hal ini penulis menyimpulkan bahwa pendataan produksi menggunakan Ms.Ecxel selain cukup rentan dari segi keamanan tentunya cara penyajian dan pendataannya masih harus memakan banyak waktu. Selain untuk meminimalisir rentannya kesalahan pencatatan data, perbaikan sistem pendataan dan pemesanan material dalam proses produksi juga memerlukan adanya sistem yang lebih mumpuni. Dengan penelitian menggunakan metode waterfall Selain membantu mempermudah dalam pengolahan data, bahan baku yang berada diarea produksi akan lebih terkontrol jumlahnya juga menjadikannya mudah mendeteksi kecurangan dalam setiap aliran data serta arus keluar barang.

Metode Pengembangan Perangkat Lunak yang digunakan adalah metode air terjun (waterfall) Menurut Rosa A.S dan Salahudin (2014:28) menjelaskan tentang metode pengembangan sistem yaitu waterfall. Metode air terjun (waterfall), sering juga disebut model sekuensial linier (sequential linear) atau alur hidup klasik (classic life cycle). Metode air terjun menyediakan pendekatan alur hidup terurut, yaitu diantaranya tahapan analisis, desain, implementasi, testing, maintenance. Tahap analisis yaitu informasi pendataan dan pelaporan dari hasil kegiatan produksi yang sedang berjalan. Serta melihat secara langsung prosedure dari tiap-tiap proses kegiatan produksi, Tahap desain berdasarkan analisa dengan cara melihat secara langsung kebutuhan dari data yang akan disajikan bagi user, serta mempertimbangkan kegiatan yang membutuhkan data yang terstruktur ataupun tidak. Dengan menuangkannya dalam prototype program yang didesain untuk kebutuhan user, Tahap implementasi berdasarkan translasi dari sistem yang telah dirancang untuk memenuhi kebutuhan user berdasarkan analisa yang telah dilakukan, Tahap testing dilakukan pada sistem, mengguunakan metode black box testing berdasarkan logika dan fungsional yang telah dirancang oleh penulis, hal ini dilakukan untuk meminimalisir terjadinya kesalahan pada rancangan sistem dan hasil dari implementasi ini sesuai dengan kebutuhan user. Tahap maintenance termasuk diantaranya instalasi dan proses perbaikan sistem apabila ditemukan adanya kesalahan/bug yang tidak ditemukan pada tahap testing.

Teknik pengumpulan data yang digunakan penulis adalah observasi yaitu dengan mengadakan pengamatan langsung kepada bagian produksi mulai dari alur berjalannya produksi hingga kegiatan yang dilakuakan oleh user, sehingga dapat diketahui prosedur dan sistem berjalan pada saat itu, sebagai acuan pembuatan sistem usulan. Wawancara (Interview) dengan menanyakan informasiinformasi yang berhubungan dengan proses produksi kepada Bpk. Rival Aulia P. selaku Leader pada bagian produksi serta mencari kebutuhan data pada Saudari Arviska U. sebagai administrasi produksi yang akan menjadi user dari rancangan program ini. Studi pustaka dengan kajian literatur yang berkaitan dengan judul tugas akhir ini, juga kajian dari jurnal-jurnal yang terkait dari web yang digunakan dan bertujuan untuk mendukung data yang telah didapat dalam referensi buku-buku yang berkaitan dengan objek riset ini.

Ruang lingkup dibatasi dengan menu login, menu data master, menu transaksi, menu actual stock, menu laporan dan menu utility.

\section{LANDASAN TEORI}

\subsection{Konsep Dasar Sistem}

Produksi merupakan kegiatan untuk menciptakan atau menambah nilai guna bagi suatu barang untuk memenuhi kebutuhan. Kegiatan produksi bagi perusahaan manufactur merupakan inti dari kegiatan perusahaan dimana jika produksi tidak berjalan dengan baik maka seluruh siklus dalam perusahaan tersebut akan mengalami kondisi yang tidak baik. Dengan demikian selain kegiatan produksi, data hasil produksipun wajib dikontrol dengan baik agar menciptakan siklus kegiatan manajemen perusahaan yang kondusif.

\subsubsection{Sistem}

Sistem menurut Sutabri dalam jurnal Apriliah, W., Ningsih, R., \& Ariyanti, N. (n.d.) (2012: 10) "Sistem dapat diartikan sebagai suatu kumpulan atau himpunan dari sistem, komponen, atau variabel yang terorganisir, saling berinteraksi, saling tergantung satu sama lain dan terpadu". 
Jurnal Inkofar * Volume 1 No. 1 Juli 2019 * ISSN: 2615-3645 (Print) / 2581-2920 (Online)

Tersedia secara online di: http://www.politeknikmeta.ac.id/meta/ojs/

\subsubsection{Model Pengembangan Software}

Menurut Rosa dan Shalahuddin dalam jurnal Sari, Ratna P., Wuryanto, A. (2015:28), "Model waterfall adalah model SDLC yang paling sederhana, model ini hanya cocok untuk pengembangan perangkat lunak dengan spesifikasi yang tidak berubah-ubah". Model SDLC air terjun (waterfall) sering juga disebut model sekuensial linier (sequential linear) atau alur hidup klasik (classic life cycle). Berikut ini adalah tahapan model air terjun:

\subsection{Teori Pendukung}

\subsubsection{Entity Relationship Diagram (ERD}

Sukamto dan Shalahuddin (2014:289), "Entitiy Relationship Diagram (ERD) adalah pemodelan awal basis data yang akan dikembangkan berdasarkan teori himpunan dalam bidang matematika untuk pemodelan basis data relasional".

\subsubsection{Unified Modelling Language (UML)}

Menurut Pratama (2014:48) mengemukakan bahwa UML (Unified Modeling Language) merupakan standarisasi internasional untuk notasi yang berbentuk grafik, yang menjelaskan tentang analisis dan design perangkat lunak yang dikembangkan dengan pemograman berorientasi objek.

A. Use Case Diagram

Use Case Diagram menurut Widodo (2011:10) Diagram use case bersifat statis, yang memperlihatkan himpunan Use Case dan aktor-aktor (suatu jenis khusus dari kelas) dan menggambarkan apa saja aktifitas yang dilakukan oleh suatu sistem dari sudut pandang pengamatan luar. Diagram ini terutama sangat penting untuk mengorganisasi dan memodelkan perilaku suatu sistem yang dibutuhkan serta diharapkan pengguna yang menjadi persoalan itu apa yang dilakukan bukan bagaimana melakukannya. Use Case Diagram menggambarkan fungsionalitas yang diharapkan dari sistem.

B. Activity Diagram

Activity Diagram adalah pemodelan aliran sistem dan merupakan kontrol dari aktivitas satu ke aktiivtas lainnya yang merupakan penggambaran proses bisnis.

C. Squence Diagram

Squence Diagram menurut Munawar (2005:187) adalah grafik dua dimensi dimana obyek ditujukan dalam dimensi horizontal, sedangkan lifeline ditunjukan dalam dimensi vertikal.

D. Class Diagram

Class Diagram menurut Munawar (2005:28) merupakan himpunan dari objek-objek yang sejenis. Sebuah objek memiliki keadaan sesaat (state) dan perilaku (behavior). State sebuah objek adalah kondisi objek tersebut yang dinyatakan dalam attribute. Sedangkan perilaku suatu objek mendefinisikan bagaimana sebuah objek bertindak dan memberikan. Rancangan Arsitektur Perangkat Lunak menggambarkan desain sistem dari sistem yang akan dibuat.

\section{PEMBAHASAN}

\subsection{Analisa Sistem Berjalan}

3.1.1. Prosedur sistem berjalan

Berdasarkan prosedur perusahaan yang saat ini berlaku, dapat diuraikan secara umum prosedur sistem berjalan saat ini sebagai berikut:

1. Prosedur Penyediaan bahan baku

Sebelum dilaksanakannya proses produksi, bagian PPIC akan memberikan Schadule Plan Produksi untuk satu bulan berdasarkan forcast dari custumer. PPIC mengirimkan schedule plan melalui email kepada supervisor dan leader selaku penanggung jawab produksi. Kemudian leader memberikan kanban (label stock) request dan membuat yang kemudian diserahkan kebagian warehouse material untuk disupplay kebutuhan material pada hari tersebut hingga satu minggu kedepan. Namun biasanya leader sudah memperhitungkan terlebih dahulu kebutuhan untuk satu minggu kedepan.

2. Prosedur Proses Produksi

Proses pertama dari rangkaian urutan produksi yaitu proses Extruder atau pelelehan dan pembentukan bahan mentah atau karet menjadi bentuk selang dengan ketentuan ukuran yang sudah distandarisasikan. Setelah proses selesai, Kemudian masuk pada proses selanjutnya yaitu proses AutoClave atau pemanggangan hose dengan standar temperatur yang berbeda-beda. Setelah proses tersebut selesai hasil proses produksi disortir untuk menentukan produk OK atau NG. Kemudian masuk ke proses terakhir yaitu perakitan hose yang digabungkan dengan berbagai aksesoris tambahan 
yang kemudian akan dicek kembali oleh Finishing Check, kemudian hasil cek tersebut dicatat dalam PCRS (Production Control Record Sheet) dan Daily Report Finishing.

3. Prosedur Laporan Produksi

Pada setiap akhir bulan berjalan selalu dilakukan inventory stock barang atau hose produksi yang dilakukan dengan cara perhitungan manual secara fisik oleh operator. Setelah data tersebut terkumpul kemudian admin produksi dmencocokkan dengan data hasil produksi Finishing. Kemudian admin produksi membuat laporan hasil produksi untuk produk yang sudah dinyatakan OK dan jumlah produk yang dinyatakan NG yang kemudian akan di laporkan kepada Suppervisor untuk ditandatangani dan dilaporkan kembali kepada Factory Manager.

\subsubsection{Permasalahan Pokok}

1. Pengumpulan data yang hanya dilakukan diakhir proses produksi yaitu proses finishing, sangat beresiko dalam penyalah gunaan barang yang tidak terdeteksi jumlah dan kondisinya. Karena dalam dua proses sebelumnya yaitu proses Extrud dan Curring tidak ada dokumen yang dibuat sebagai laporan sehingga sulit mengontrol berapa banyak barang yang rusak dan terbuang. Selain berpotensi keliru pada saat inventory juga dapat menghilangkan history dalam proses produksi itu sendiri.

2. Permintaan material request yang tidak disertakan dengan dokumen tertulis juga menjadi kelemahan dalam sebuah sistem informasi perusahaan. Selain potensi kesalahan informasi yang rentan, tentunya akan memberi kesempatan bagi pihak tidak bertanggung jawab untuk melakukan kecurangan. Tentunya hal tersebut harus dihindari dan diantisipasi.

3. Pelaporan hasil produksi yang membutuhkan waktu lama karna penyimpanan dokumen masih dalam bentuk manual yaitu Ms. Excel, membuat staff admin produksi cukup kesulitan dan membutuhkan waktu yang banyak dalam pengumpulan datanya.

\subsubsection{Pemecahan Masalah}

1. Pembuatan sebuah sistem baru yang akan memisahkan hasil produksi dari setiap proses mulai dari pencatatan hasil produksi Extrud dan pencatatan hasil produksi Curring. Agar lebih mudah mendeteksi kondisi dan lokasi proses mana barang tersebut berada.

2. Pembuatan form request material baik dalam bentuk hardcopy maupun program sistem usulan.

3. Pembuatan laporan yang lebih terkontrol dengan periode yang lebih spesifik, dibuatkan form Laporan yang akan menghasilkan laporan Mingguan, Bulanan, hingga Tahunan.

\subsection{Perancangan Sistem Usulan}

3.2.1. Tahapan Perancangan Sistem

A. Rancangan Diagram Use Case

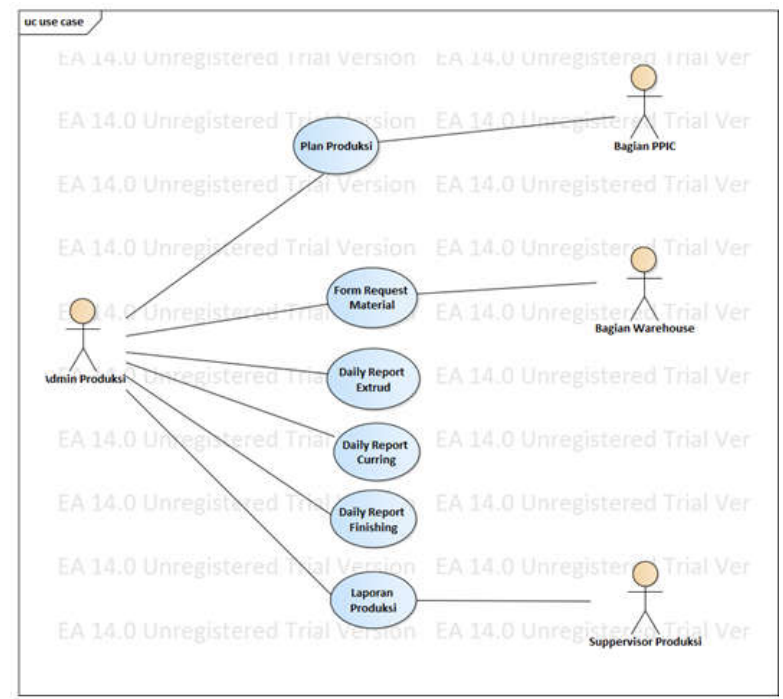

Gambar 1. Diagram Use Case Kegiatan sistem usulan Produksi 
Jurnal Inkofar * Volume 1 No. 1 Juli 2019 * ISSN: 2615-3645 (Print) / 2581-2920 (Online)

Tersedia secara online di: http://www.politeknikmeta.ac.id/meta/ojs/

B. Rancangan Diagram Aktivitas

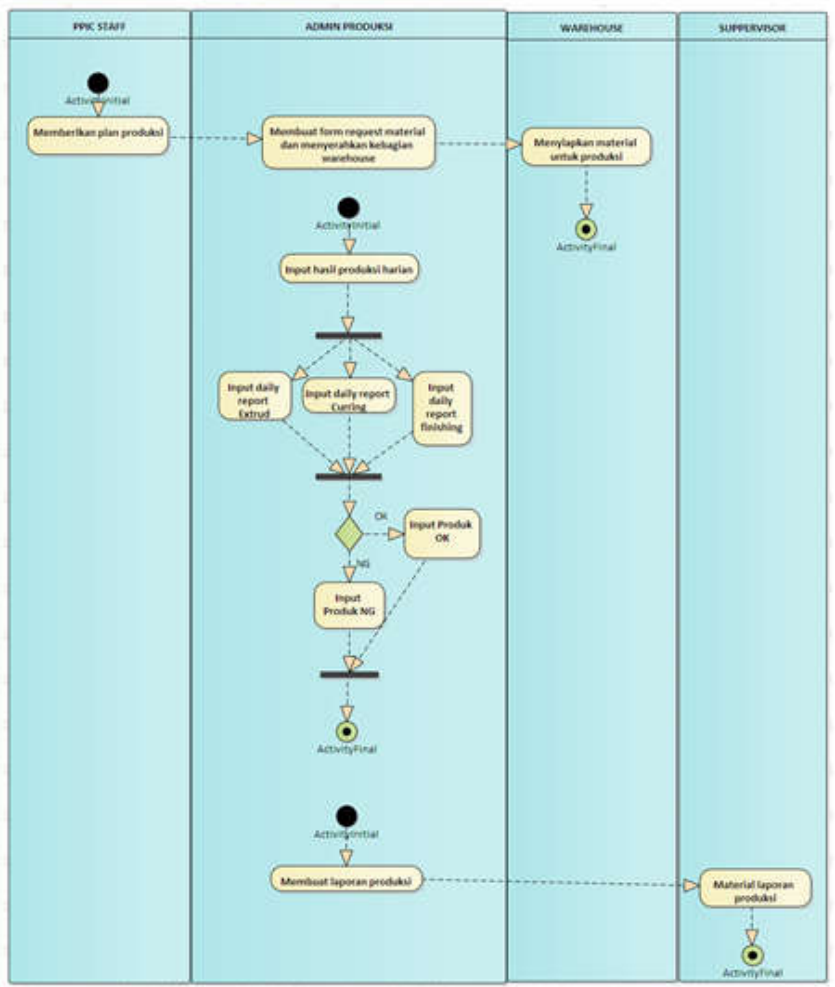

Gambar 2. Diagram Activity Sistem Informasi Produksi

C. Rancangan Class Diagram

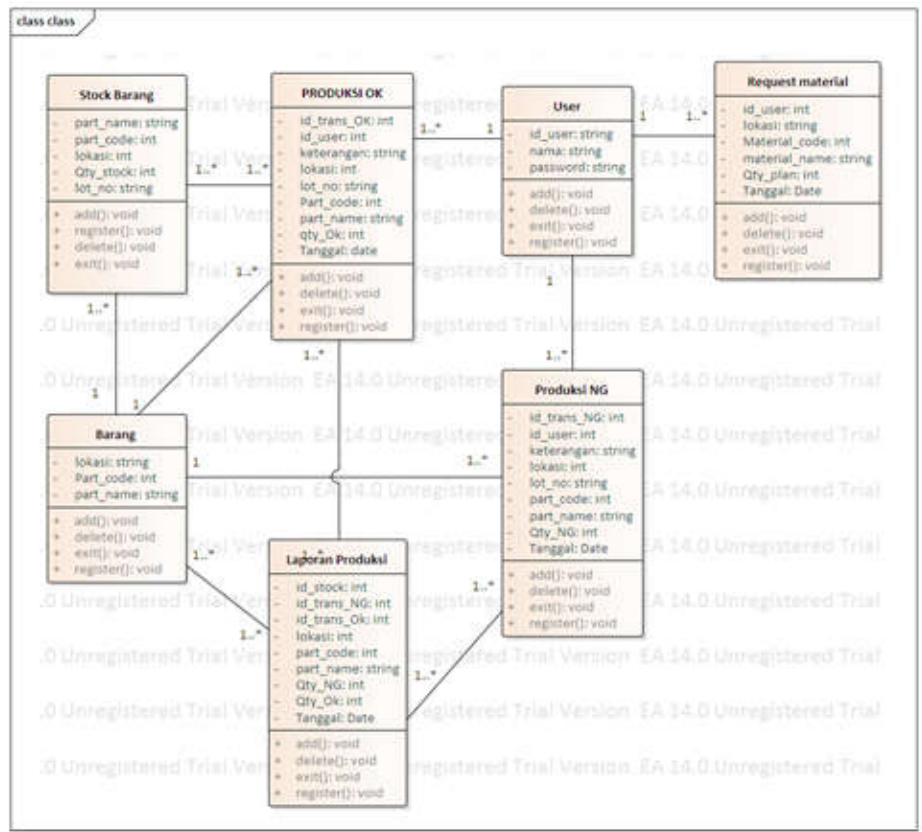

Gambar 3. Class Diagram Sistem Informasi Produksi 
D. Rancangan Sequence Diagram

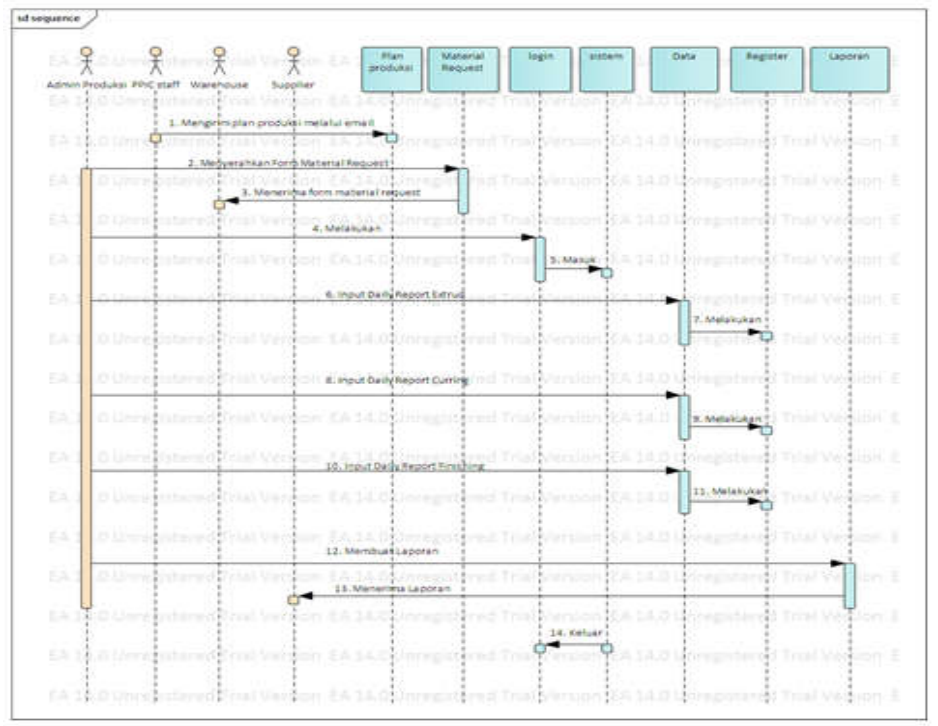

Gambar 4. Sequence Diagram Sistem Informasi Produksi

\subsubsection{Implementasi}

A. Tampilan Login User

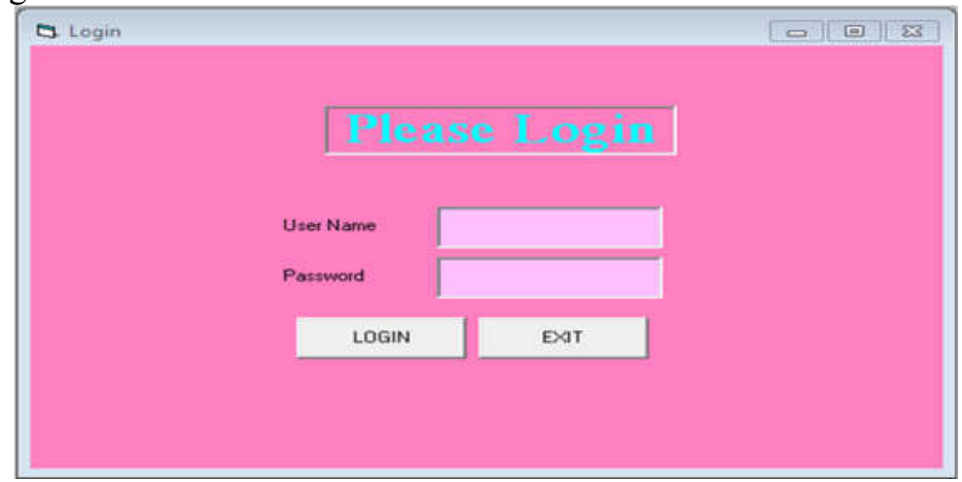

Gambar 5. Tampilan Login User

B. Tampilan Menu Utama Program Produksi Hose Come Fuel Feed

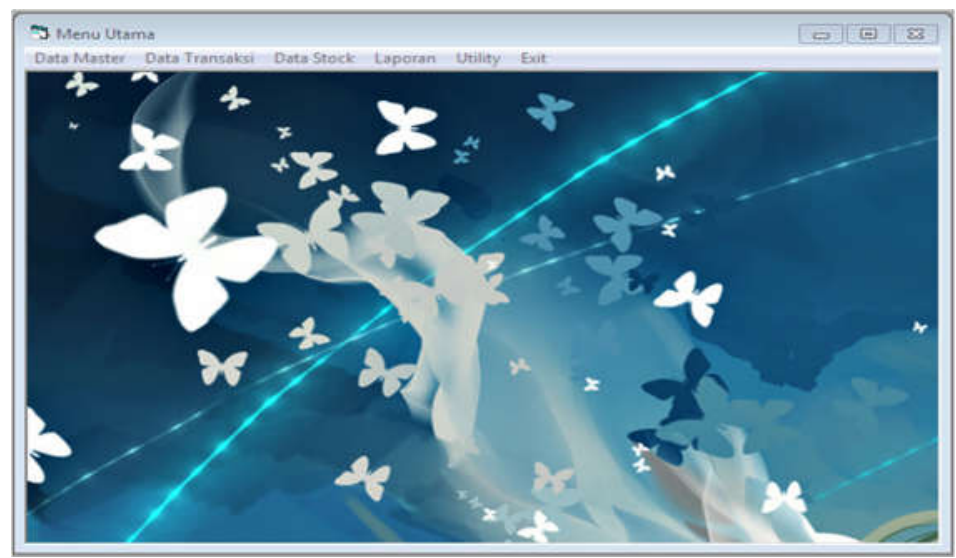

Gambar 6. Tampilan Menu Utama Program Produksi Hose Come Fuel Feed 


\section{KESIMPULAN}

Dalam Pembahasan sistem informasi produksi yang diamati oleh penulis, maka penulis dapat menyimpulkan hasil pengamatan sebagai berikut:

a. Pembuatan gagasan sistem terkomputerisasi dan penambahan pendataan dalam setiap perpindahan proses produksi diharapkan dapat memenuhi target percapaian melalui kontrol data stock dari hasil produksi. Untuk memudahkan dan dapat memanfaatkan waktu dengan baik dari hasil pembuatan perancangan sistem usulan ini.

b. Pembuatan prosedur pemesanan material produksi menggunakan sistem terkomputerisasi akan lebih memperbaiki data sebagai bukti pemesanan pada pihak warehouse. Dalam hal ini diharapkan dapat mengurangi kekeliruan atau kurangnya ketelitian dalam penyediaan bahan baku.

c. Tentunya dalam sistem yang baik diharapkan dapat memaksimalkan hasil dan kinerja dari karyawan dan pencapaian yang baik bagi perusahaan.

\section{DAFTAR PUSTAKA}

A. S Rosa, dan M. Shalahuddin. 2014. Rekayasa Perangkat Lunak Struktur dan Berorientasi Objek. Bandung: Informatika.

Agus Eka, Pratama. 2014. Sistem Informasi dan Implementasinya. Bandung: Informatika Bandung. Apriliah, W., Ningsih, R., \& Ariyanti, N. (n.d.). Rancang Bangun Sistem Informasi Penerimaan dan Pengeluaran Kas pada PT. Rhadogel Gums Internasional Bekasi, Jurnal Inkofar * Volume 1 No. 2, Desember 2018 * ISSN: 2615-3645, 28-39.

Munawar. 2005. Pemodelan Visual Menggunakan UML. Yogyakarta: Graha Ilmu.

Sari, Ratna P., Wuryanto, A. Perancangan Sistem Informasi Administrasi Pembinaan K3 pada PT. Exaudi Bina Karya, Jurnal Inkofar * Volume 1 No. 1, Juli 2018 * ISSN: 2615-3645.

Widodo, P. P., \& Herlawati. 2011. Menggunakan UML Informatika. Bandung: Andi.

\section{UCAPAN TERIMAKASIH}

Kepada keluarga besar penulis yang selama ini setia mendukung karir penulis dan teman - teman seperjuangan yang tidak bisa disebutkan satu persatu. 